\title{
Decolourisation of Different Dyes by two Pseudomonas Strains Under Various Growth Conditions
}

\author{
Ewa Zabłocka-Godlewska • Wioletta Przystaś • \\ Elżbieta Grabińska-Sota
}

Received: 30 July 2013 / Accepted: 11 December 2013 / Published online: 22 January 2014

(C) The Author(s) 2014. This article is published with open access at Springerlink.com

\begin{abstract}
The aim of the present study was the decolourisation of mixture of two dyes belonging to different groups by two Pseudomonas fluorescens strains (Sz6 and SDz3). Influence of different incubation conditions on decolourisation effectiveness was evaluated. Dyes used in the experiment were diazo Evans blue (EB) and triphenylmethane brilliant green (BG). Another goal of the experiment was the estimation of toxicity of process by-products. Incubation conditions had a significant influence on the rate of decolourisation. The best results were reached in shaken and semistatic samples (exception Evans blue). After $24 \mathrm{~h}$ of experiment in semistatic conditions, BG removal reached up to $95.4 \%$, EB $72.8 \%$ and dyes mixture $88.9 \%$. After $120 \mathrm{~h}$, all tested dyes were completely removed. In most cases, dyes were removed faster and better by strain Sz6 than SDz3. At the end of the experiment, in majority of the samples, decrease of phyto- and zootoxicity was observed.
\end{abstract}

Keywords Pseudomonas - Azo dye - Triphenylmethane dye $\cdot$ Decolourisation $\cdot$ Zootoxicity $\cdot$ Phytotoxicity

\footnotetext{
E. Zabłocka-Godlewska $(\bowtie) \cdot$ W. Przystaś •

E. Grabińska-Sota

Environmental Biotechnology Department, Silesian

University of Technology,

Akademicka 2A, 44-100 Gliwice, Poland

e-mail: ewa.zablocka-godlewska@polsl.pl

W. Przystaś

e-mail: wioletta.przystas@polsl.pl

E. Grabińska-Sota

e-mail: elzbieta.g.sota@polsl.pl
}

\section{Introduction}

Synthetic dyes especially azo and triphenylmethane ones are used in many industrial branches for dyeing of wool, cotton, nylon, leather, paper, cosmetics, pharmaceuticals, food, plastic, petroleum products, etc. (Hamid and Rehman 2009; Koyani et al. 2013; Padamavathy et al. 2003; Somasiri et al. 2006; Swamy and Ramsay 1999; Tony et al. 2009; Younes et al. 2012). There are 100,000 commercially available dyes. Annual global dyes production reaches almost $7 \times 10^{7}$ t. Among the 12 classes of dyes, the majority (70\%) are azo dyes containing one or more azo groups. Because of the imperfection of dyeing process, approximately 10 $15 \%$ of the synthetic dyes is released into the industrial waste, causing serious environmental problems worldwide (Hamid and Rehman 2009; Koyani et al. 2013; Tony et al. 2009; Silveira et al. 2009). Inadequate treatment of coloured wastewaters may lead to contamination of surface waters. The consequence is reduction of the penetration of light, photosynthetic activity and deficiency of oxygen. Synthetic origin of dyes and complex aromatic molecular structure cause that many ofthem are toxic and mutagenic, resistant to biological degradation and may be accumulated in the food chain (Azmi et al. 1998; Banat et al. 1996; Forgacs et al. 2004; Hamid and Rehman 2009; Koyani et al. 2013; Pointing and Vrijmoed 2000; Sani and Banerjee 1999). Increasing use of dyes causes an increase of their concentration in the environment and requires the development of new, environmentally and economically 
acceptable treatment technology. Currently available physicochemical methods (chemical oxidation, reverse osmosis, adsorption, flotation, precipitation, coagulation) are very effective but are costly, energy intensive, have limited use and can lead to the production of toxic by-products and a large amount of sludges (Eichlerova et al. 2006; Hamid and Rehman 2009; Hu 2001; Koyani et al. 2013; Tony et al. 2009). In comparison with the methods mentioned above, the methods based on microbial removal of dyes tend to be more attractive and are becoming more and more popular. Microbial degradation of dyes is gaining importance as an ecological, economical, less invasive alternative treatment techniques (Forgacs et al. 2004; Hamid and Rehman 2009; Koyani et al. 2013; Saratale et al. 2011; Silveira et al. 2009; Singh and Pakshirajan 2010; Srinivasan and Viraraghavan 2010; Tony et al. 2009; Younes et al. 2012; Zabłocka-Godlewska et al. 2012). Literature describes the participation of different taxonomic groups of organisms (bacteria, fungi, algae, plants) in the dyes decolourisation. The most popular are the technologies based on biodegradation/biotransformation of dyes by living bacteria or fungi. A lot of studies especially in case of fungi are concentrated on physical sorption on living or dead biomass. These technologies are more attractive than physical and chemical treatment methods due to low operating costs, high effectiveness and environmental harmlessness (An et al. 2002; Chen et al. 2003; Wang et al. 2012; Wu et al. 2009, 2012). Bacteria used in these technologies are applied as a single strain, co-cultures of strains or mixed bacterial cultures. The most popular genera of bacteria described in literature are Pseudomonas, Bacillus, Sphingomonas, Aeromonas, Citrobacter, Escherichia, Desulphovibrio, Proteus, Schewanella and Alcaligenes (An et al. 2002; Nigam et al. 1996; Saratale et al. 2011; Sharma et al. 2004; Tony et al. 2009; Wang et al. 2012).

It was proven that the efficiency of dye removal depends on the type of microorganisms and the process conditions. The most important factors are temperature, oxygen level, $\mathrm{pH}$, additional available carbon and nitrogen sources, as well as the concentration of the dye and its chemical structure (Azmi et al. 1998; Banat et al. 1996; Forgacs et al. 2004; Hamid and Rehman 2009; Koyani et al. 2013; Padamavathy et al. 2003; Pointing and Vrijmoed 2000; Przystaś et al. 2009; Sani and Banerjee 1999; Saratale et al. 2011; Stolz 2001; Swamy and Ramsay 1999; Tony et al. 2009; Younes et al. 2012; Zabłocka-Godlewska et al. 2009).
Abilities of two strains of Pseudomonas fluorescens isolated from two different wastewater treatment plants for decolourisation of various structurally dyes were studied previously (Zabłocka-Godlewska et al. 2012). Five different dyes belonging to three different groups were examinated (two fluorone dyes, triphenylmethane brilliant green and crystal violet and azo Evans blue). Results of test of decolourisation potential showed significant differences between abilities of both tested strains. Triphenylmethane and azo dyes were more efficiently removed by Sz6 strain isolated from small treatment plant. Removal of triphenylmethane dyes was more effective than other examined groups. Strain Sz6 removed almost all colour in samples with triphenylmethane dyes regardless of dye concentration and structure and strain SDz3 only in samples with dyes concentration $0.05 \mathrm{gl}^{-} 1$. Higher content of dyes $\left(0.1 \mathrm{gl}^{-} 1\right)$ was removed by this strain in $62 \%$ for crystal violet and $46 \%$ for brilliant green.

Most researches are focused on the removal of individual dyes from wastewater, whereas the coloured wastewater contains a mixture of them. Relatively few studies on mixtures of dyes were conducted. In general, these studies were focused on dyes belonging to the same group (mainly azo group), (Saratale et al. 2010; Singh and Pakshirajan 2010; Tony et al. 2009; Vijaykumar et al. 2007). In addition, information about ecotoxicity of the biotransformation products is limited. In our study, we focused our attention on the removal efficiency of dyes mixture by two Pseudomonas strains. The mixture was prepared from dyes belonging to two different groups (azo and triphenylmethane) that was not investigated in any others studies. These two groups of dyes are more frequently used for dying processes and may be found in effluents. Such mixture may be more difficult for removal than single dyes as well as mixture of dyes from one family. Another goal of our study was to evaluate the ecotoxicological impact on aquatic organisms of biotransformation products.

\section{Materials and Methods}

\subsection{Bacterial Strains Used in the Experiment}

Bacterial strains used in experiment Sz6 and SDz3 were isolated from two different wastewater treatment plants in south Poland. Both selected strains were classified by the API 20NE test (Biomerieux) as Pseudomonas fluorescens (Zabłocka-Godlewska et al. 2012). 
Species from Pseudomonas genus are Gramnegative, aerobic rod-shaped bacteria belonging to the family Pseudomonadaceae, almost all strains are motile (a single polar flagellum). As Gram-negative bacteria, they have thin cell wall containing up to $10 \%$ of peptidoglycan and outer membrane composed of proteins, phospholipids and lipopolysaccharides. Strains Pseudomonas fluorescens are free-living bacteria, commonly found in environment (soil, water, effluents, surface of plants, animals, they are natural component of human and animal intestinal microflora), some of them may be pathogens (Salyers and Whitt 2000; Schlegel 1993).

\subsection{Influence of Dyes Concentration on Decolourisation Effectiveness}

Influence of five different concentrations $(0.01,0.025$, $0.05,0.075$ and $0.1 \mathrm{gl}^{-1}$ ) of Evans blue (ZabłockaGodlewska et al. 2012) and brilliant green (Table 1) on decolourisation effectiveness was estimated. The dyes mixture was prepared at the equal proportion (1:1) of both dyes. Influence of six different concentrations of dyes mixture $\left(0.02,0.04,0.06,0.08,0.1\right.$ and $0.12 \mathrm{gl}^{-1}$ ) on decolourisation effectiveness was estimated. Tube test on liquid Kimura medium was done in triplicate. Bacterial strains inoculums were prepared from $48 \mathrm{~h}$ slants (Nutrient Agar (Fluka Biochemika)) washed with physiological salt solution (suspension density estimated by the McFarland scale was 5). Filter-sterilised colourants were added to tubes containing $10 \mathrm{ml}$ of 48 -h old cultures in stationary growth phase $(15 \times$ $10^{8} \mathrm{cfu} \mathrm{ml}^{-1}$ ). After 6 days of incubation in $26^{\circ} \mathrm{C}$, absorbance was measured spectrophotometrically on UV-Vis Hitachi U-1900 (determined optimum wavelength for Evans blue was $\max -606 \mathrm{~nm}$, for brilliant

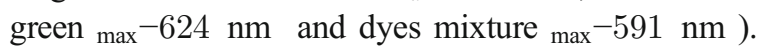
Percentage of dye removal was calculated according to Formula 1.

$\mathrm{R}=((C-S / C) \times 100 \%$

$\mathrm{R}$ Dye removal [\%]

C Concentration of dye in a control sample $\left[\mathrm{mg} \mathrm{l}^{-1}\right]$

$\mathrm{S}$ Residue concentration of dye in sample with bacteria biomass $\left[\mathrm{mg} \mathrm{l}^{-1}\right]$

Table 1 Characteristic of used dyes

\begin{tabular}{|c|c|c|c|c|}
\hline Dye & Structure & Class & C.I number & $\lambda \max$ \\
\hline $\begin{array}{l}\text { Brilliant } \\
\text { green }\end{array}$ & & triarylmethane & 42040 & 624 \\
\hline Evans & & diazo & 23860 & 606 \\
\hline
\end{tabular}




\subsection{Influence of Growth Conditions on Dyes Removal}

The main experiment was prepared in a similar way as the previous test, the difference was that the inoculum ( $1 \mathrm{ml}$ ) was added to $300 \mathrm{ml}$ flasks containing $100 \mathrm{ml}$ of Kimura medium. On the basis of the results of previous tests, concentrations of dyes chosen for experiment with single dyes were $0.05 \mathrm{gl}^{-1}$ for Evans blue (ZabłockaGodlewska et al. 2012) and $0.1 \mathrm{gl}^{-1}$ for brilliant green. Dyes concentration in sample with mixture was 0.08 $\mathrm{gl}^{-1}\left(0.04 \mathrm{gl}^{-1}\right.$ Evans blue and $0.04 \mathrm{gl}^{-1}$ brilliant green (Sigma-Aldrich)). Water solution of dyes was filtersterilised (Millipore cellulose filters $\varnothing 0.20 \mu \mathrm{m}$ ) and added to 48-h old bacterial samples (stationary growth phase). Cultures were incubated in static, semistatic and shaken conditions in $26{ }^{\circ} \mathrm{C}$. Dead biomass (biomass autoclaved for $20 \mathrm{~min}$ in $121{ }^{\circ} \mathrm{C}, 1.5 \mathrm{~atm}$.) was used for estimation of biosorption. Absorbance was measured after 1, 6, 24, 48, 72, 96 and $120 \mathrm{~h}$ of incubation (UV-Vis spectrophotometer Hitachi U1900). The wavelengths for Evans blue (606 nm), brilliant green $(624 \mathrm{~nm})$ and dyes mixture $(591 \mathrm{~nm})$ were determined experimentally as the wave with maximal absorbance. Percentage of dye removal was calculated the same as previously according to Formula (1).

\subsection{Toxicity Evaluation}

The zootoxicity was evaluated using Daphnia magna (OECD 202) and phytotoxicity using OECD Lemna sp. growth inhibition test no. 221. Tests were performed in quadruple. EC50 value was estimated. On the basis of these data, acute toxicity unit (TUa) was calculated (Formula 2) and toxicity class was established.

$\mathrm{TUa}=100 / \mathrm{EC} 50$

where

EC50 is the effective concentration of a wastewater sample that causes $50 \%$ inhibition of tested organisms.

Samples were classified according to ACE 89/BE 2/D3 Final Report Commission EC (TUa $<0.4$-non toxic (I class); $0.4 \leq \mathrm{TUa}<1.0$ - low toxicity (II class); $1.0 \leq \mathrm{TUa}<10$ - toxic (III class); $10 \leq \mathrm{TUa} \leq 100$ high toxicity (IV class); TUa $>100$ — extremely toxic (V class)).

\section{Results and Discussion}

3.1 Influence of Dyes Concentration on Decolourisation Effectiveness

Influence of dyes concentrations (BG and mixture) was evaluated (Fig. 1a, b). Results for Evans blue were already presented (Zabłocka-Godlewska et al. 2012). Increase of Evans blue concentration up to $0.075 \mathrm{gl}-{ }^{1}$ caused decrease of effectiveness of decolourisation by strain SDz3. For further study, the dye concentration $0.05 \mathrm{gl}-{ }^{1}$ was chosen (Zabłocka-Godlewska et al. 2012). Brilliant green was better removed than Evans blue (Fig. 1a). Concentration $0.1 \mathrm{gl}-{ }^{1}$ of brilliant green was removed by strain SDz3 in $84 \%$ and by strain Sz6 in $72.7 \%$. Strain SDz3 almost completely removed this dye in concentrations $0.01-0.05 \mathrm{gl}^{-1}$. Second tested strain (Sz6) removed BG in more than $95 \%$ when concentration was between 0.01 and $0.05 \mathrm{gl}^{-1}$. For further researches, this concentration of dye was chosen. Examined dyes belong to different groups, and different microbial decolourisation mechanism is involved in the process. The first step of microbial decolourisation of azo dyes is generally anaerobic process, which involves azoreductase enzymes activity and also oxygen insensitive azoredictase (Ola et al. 2010; Khalid et al. 2008; Nachiyar and Rajakumar 2005). Bacterial decolourisation of triphenylmethane dyes needs activity of triphenylmethane reductase (TMR) and in some cases cytochrome P450 (Wang et al. 2012). In our previous study (Zabłocka-Godlewska et al. 2012), strain Sz6 better removed brilliant green than Evans blue in concentration $0.1 \mathrm{gl}^{-1}$ (96.5 and $84 \%$, respectively). In case of strain SDz3, significant differences were noticed in concentration $0.05 \mathrm{gl}^{-1}$ (93.1 and $72.5 \%$, respectively). Also, in our other study (Przystaś et al. 2012), we observed that brilliant green was better removed than Evans blue when present in concentration $0.05 \mathrm{gl}^{-1}$ in samples with different bacteria strains (regardless of incubation conditions). Differences between results reached for strains belonging to the same genus were also proved by Przystas et al. (2012). Two strains of Pleurotus ostreatus fungi had a different potential for the removal of the same dyes what may be connected with adaptation to the specific conditions in site of isolation. High impact of dye concentration on decolourisation effectiveness was also presented by $\mathrm{Wu}$ et al. (2009) and Solis et al. (2012). 


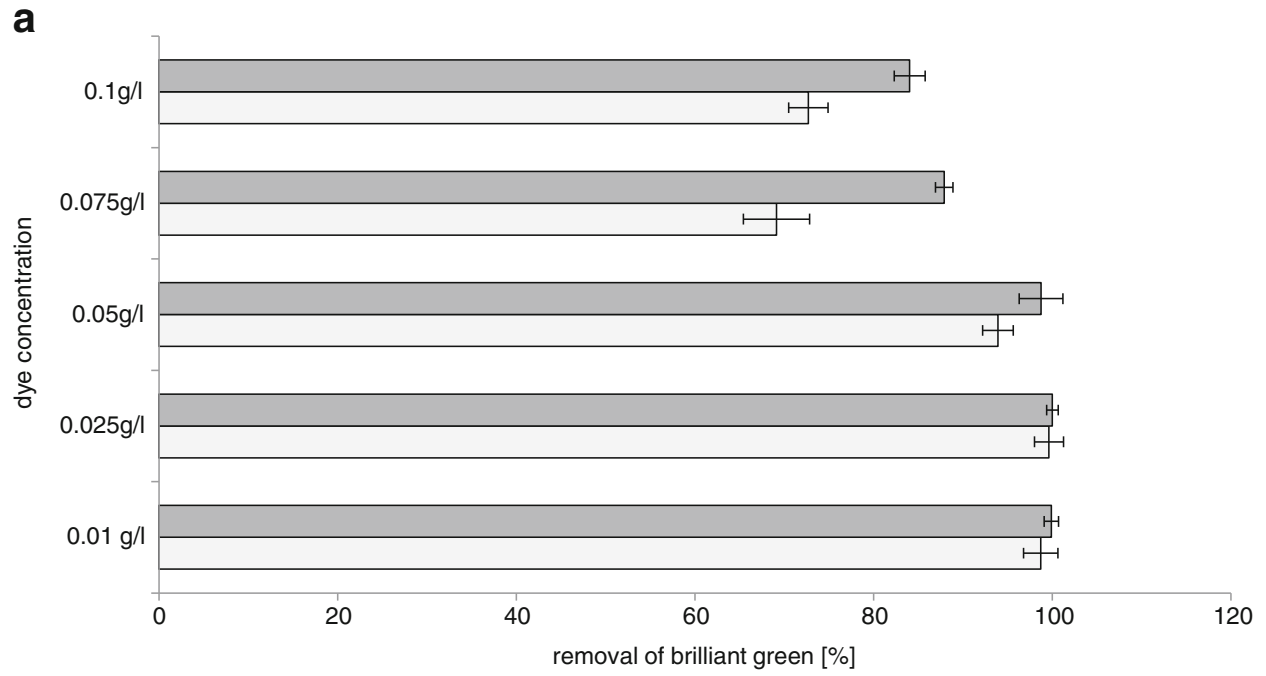

b

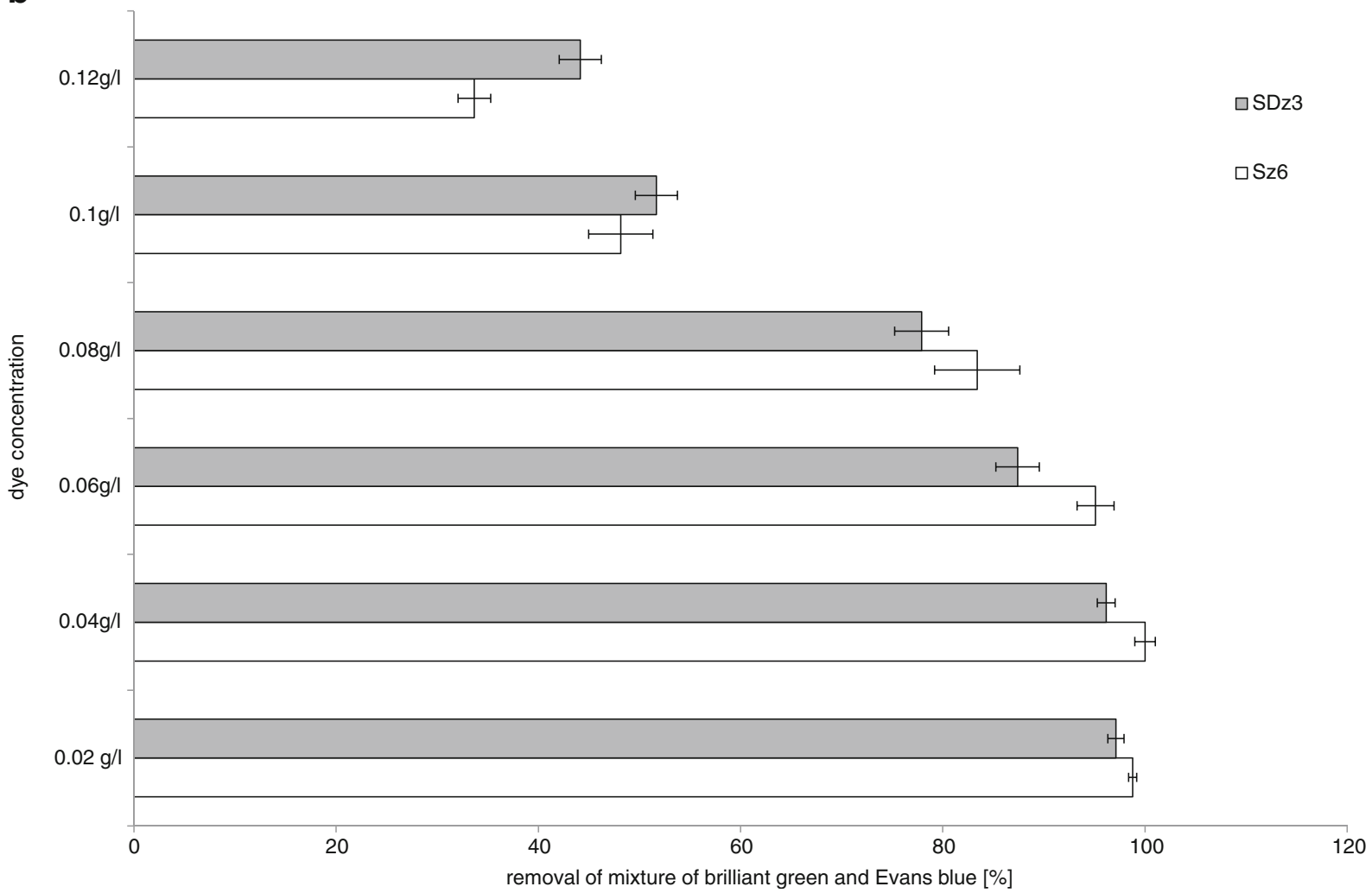

Fig. 1 Influence of brilliant green (a) and dyes mixture (b) concentration on effectiveness of their removal

Increase of concentration of dyes mixture had a significant influence on its removal by both strains (Fig. 1b). Concentrations between 0.02 and $0.08 \mathrm{gl}^{-1}$ were removed by both tested strains in more than $75 \%$. Increase of dyes mixture concentration up to $0.1 \mathrm{gl}^{-1}$ significantly decreased effectiveness of the process (removal below $50 \%$ ) As it is presented in Fig. 1b, the most appropriate mixture concentration for further studies was $0.08 \mathrm{gl}^{-1}$. 


\subsection{Influence of Growth Conditions on Dyes Removal}

The best results of removal of Evans blue were reached in static samples (Fig. 2a). These results were presented in our previous publication (Zabłocka-Godlewska et al. 2012). Strain Sz6 was more effective in dye removal than SDz3 (after $48 \mathrm{~h}$, about 96 and $87 \%$ dye removal respectively). Finally, the dye was completely removed by both strains. In comparison with the results reached in samples with Evans blue, decolourisation of brilliant green in static conditions was lower (after $48 \mathrm{~h} \mathrm{SDz} 3$ removed $66.15 \%$ and Sz6 $59.9 \%$ ). Initial concentration of brilliant green was two times higher than Evans blue. In spite of higher concentration removal of brilliant green by strain SDz3 at the end of experiment reached $91.16 \%$.

Initially, in semistatic conditions, results of removal of Evans blue (Fig. 2b) were not so good as in static samples (after $48 \mathrm{~h}$, SDz3 removed $75.1 \%$ and Sz6 $82.8 \%$ ). After $120 \mathrm{~h}$ of experiment, decolourisation by Sz6 strain reached $100 \%$ as well as dyes mixture and brilliant green. In comparison with static samples in semistatic samples, acceleration of brilliant green and dyes mixture removal by strain Sz6 was observed. After $24 \mathrm{~h}$ of experiment, the level of removal was higher than $90 \%$ and after $48 \mathrm{~h}$, complete decolourisation was observed. Effectiveness of brilliant green removal by strain SDz3 was comparable in static and semistatic conditions (after 120 h, 91.2 and $84.5 \%$, respectively). Presented results for brilliant green are similar with our previous results (Przystaś et al. 2012). Regardless of used strain, the best results of BG decolourisation were reached in shaken conditions what can suggest that oxygen is important in this process. In opposite to the result presented above for Pseudomonas fluorescens strains (Sz6 and SDz3), Evans blue was better removed by Chryseomonas luteola and Burkholderia cepacia tested earlier (Przystaś et al. 2012) in shaken samples. All of these strains are aerobic, so these results suggest involving of different biodegradation mechanisms. Higher effectiveness of triphenylmethane crystal violet decolourisation in shaken than static conditions was also reached for Citrobacter sp. by An et al. (2002).

In present studies, a positive influence of agitation on triphenylmethane dye removal by both Pseudomonas strains was noticed. In opposite to our results, Wang et al. (2011) stated that in case of Achromobacter xylosoxidans, MG1 sample agitation had no influence on triphenylmetane decolourisation. It suggests contribution of different decolourisation pathways in process. Current knowledge about triphenylmethane dyes decolourisation mechanisms is still in its infancy (Wang et al. 2011, 2012). In study of biodegradation of triphenylmethane malachite green (MG) presented by Jang et al. (2005), the triphenylomethane reductase (TMR) was shown to be responsible for the conversion of MG to colourless leucomalachite green (LMG). Wang et al. (2012) speculate that MG degradation by Exiguobacterium sp. involves the reaction of $N$-demethylation, reduction, benzene ring removal and oxidation. In the postulated pathway, the first step transforming MG to LMG is through the enzyme TMR. Cytochrome P450 most likely participated in further transformation of MG. This superfamily of hemoproteins has been also reported to be involved in triphenylomethane dyes degradation by Mycobacteria (Jones and Falkinham 2003; Wang et al. 2012). Wang et al. (2011) highlighted that decolourisation mechanism of these type of dyes might be both the intracellular and extracellular. Differences in rate and abilities for dyes decolourisation between strains are probably connected with various mechanisms of dye transformation as it was presented by Wang et al. (2012) and Wu et al. (2012).

Samples agitation had a negative influence on the effectiveness of Evans blue decolourisation (Fig. 2c). Results are also presented and described in the previous publication (Zabłocka-Godlewska et al. 2012). After 120 h, strain SDz3 removed $64.0 \%$ and Sz6 67.2 \% of dye. Decolourisation of azo dyes may occur under strictly anaerobic, facultative anaerobic or aerobic conditions. It depends on the strain and mechanism of biotransformation. Agitation caused increase of oxygen concentration in samples. Effect of agitation and changes of oxygen concentration on azoreductase activity is widely described in literature (Saratale et al. 2011). Worse decolourisation results in semistatic and shaken samples point out on possible oxygen inhibition effect on azoreductases activity. Azoreductases are responsible for the first step on decolourisation of azo dyes into simpler aromatic compounds (Saratale et al. 2011).

Results of dyes mixture removal were similar in shaken and semistatic samples (100\% dye removal after 48 h) for strain Sz6 (Fig. 2b). For this strain, results are similar to these reached for brilliant green. The rate of dyes mixture removal by strain SDz3 was slower (70.4\% in shaken sample and $68.7 \%$ in semistatic samples after $48 \mathrm{~h}$ ). After $96 \mathrm{~h}$ of experiment, difference between results reached for both strains in semistatic 
Fig. 2 Percentage removal of dyes in static (a),

semistatic (b) and shaken samples (c)

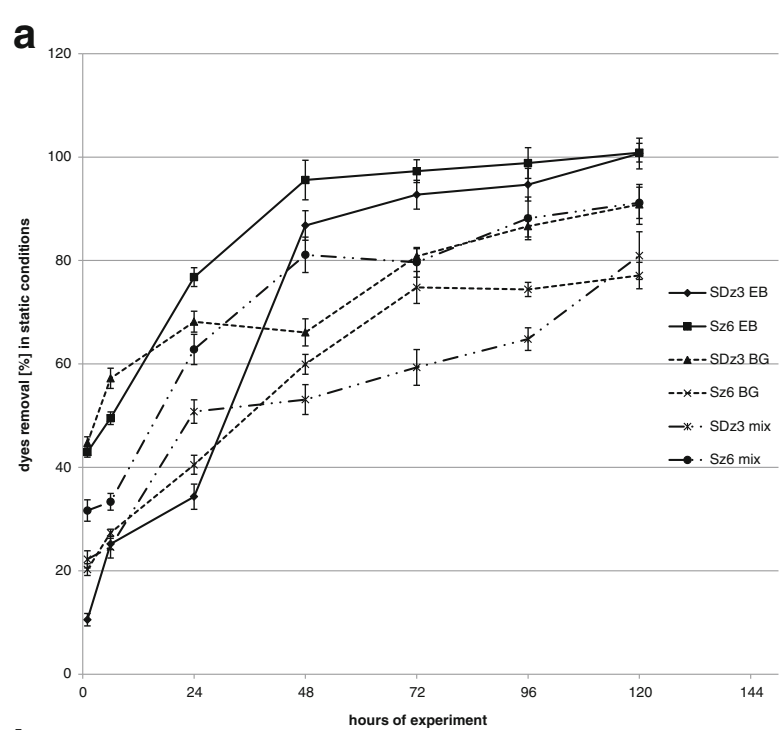

b

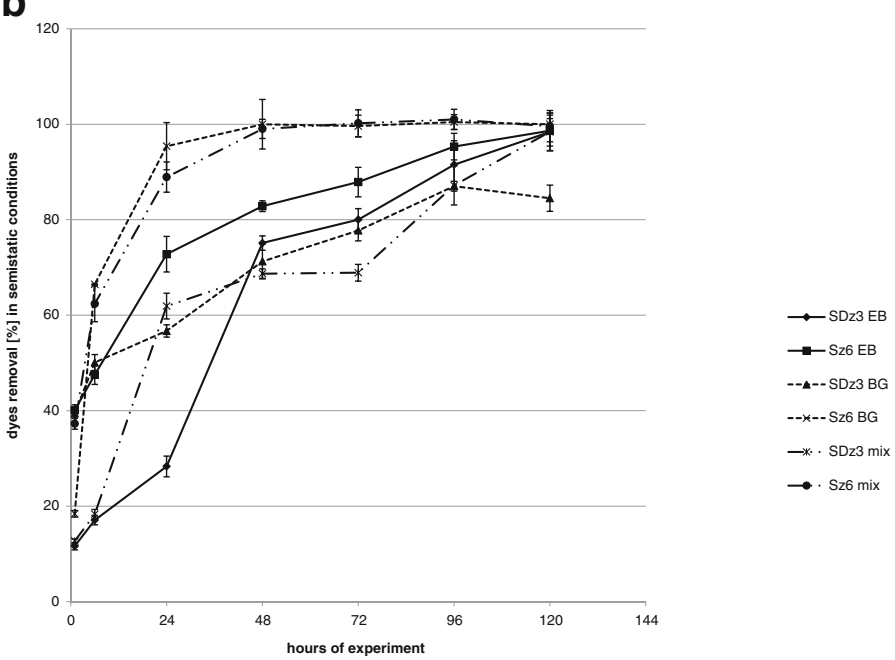

C

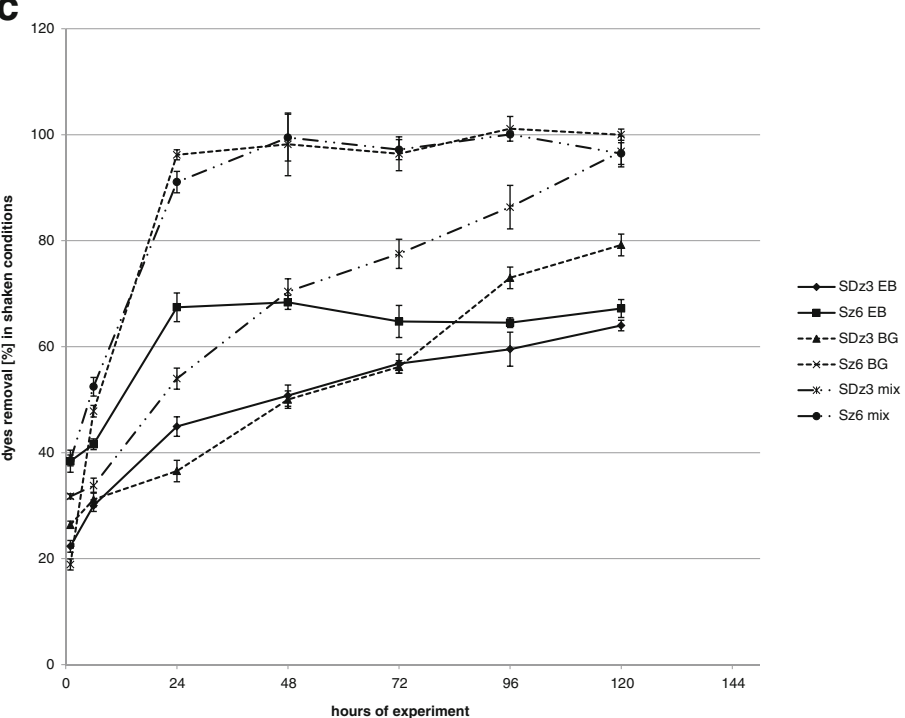


and shaken conditions was lower than $15 \%$ and finally (after $120 \mathrm{~h}$ ) strain SDz3 completely removed dyes mixture (Fig. 2b,c). In static conditions, final removal of mixture was lower, $91.2 \%$ for strain Sz6 and $81 \%$ for SDz3. These results were similar to the brilliant green removal in static sample by both strains and were lower than Evans blue decolourisation effect (Fig. 2a). Decolourisation of mixture, as well as individual tested dyes was faster in case of strain Sz6.

High decolourisation potential of Pseudomonas strains for dyes decolourisation is presented in literature. Chen (2002) used Pseudomonas luteola for decolourisation of reactive azo dyes. He proved that this process is connected with azoreductase enzyme activity and oxygen sensitive. Silveira et al. (2009) used in the experiment three different Pseudomonas species for decolourisation of 14 industrial textile dyes. The experiment was done under static anoxic conditions and proved high decolourisation potential of Pseudomonas aeruginosa and Pseudomonas oleovorans. Another study with Pseudomonas strains was carried by $\mathrm{Wu}$ et al. (2009). Decolourisation of azo and tripenymethane (TPM) dyes was examined. Crystal violet, malachite green and brilliant green (TPM) were almost completely removed by Pseudomonas otitidis WL-13 up to concentration $100 \mathrm{\mu moll}^{-1}$, where methyl red and Congo red (azo dyes) were removed in less than $45 \%$ when were present in sample in concentration $10 \mu \mathrm{moll}^{-1}(12 \mathrm{~h}$ experiment). Jadhav et al. (2010) studied the bacterial consortium composed from three Pseudomonas species in the experiment with azo dyes. Consortium had better decolourisation results than pure cultures. One of the strains (Pseudomonas sp. SUK1) used in studies describe above was also examined by Kalyani et al. (2009). The experiment was done with azo Reactive Red 2 in static conditions. Tested Pseudomonas strain was capable utilise toxic RR2 in concentration $5 \mathrm{gl}^{-1}$ in more than $70 \%$ after $108 \mathrm{~h}$ and more than $90 \%$ in concentration $2 \mathrm{gl}^{-1}$ during $48 \mathrm{~h}$. This strain decolorized with a great results azo dyes mixture. Decolourisation

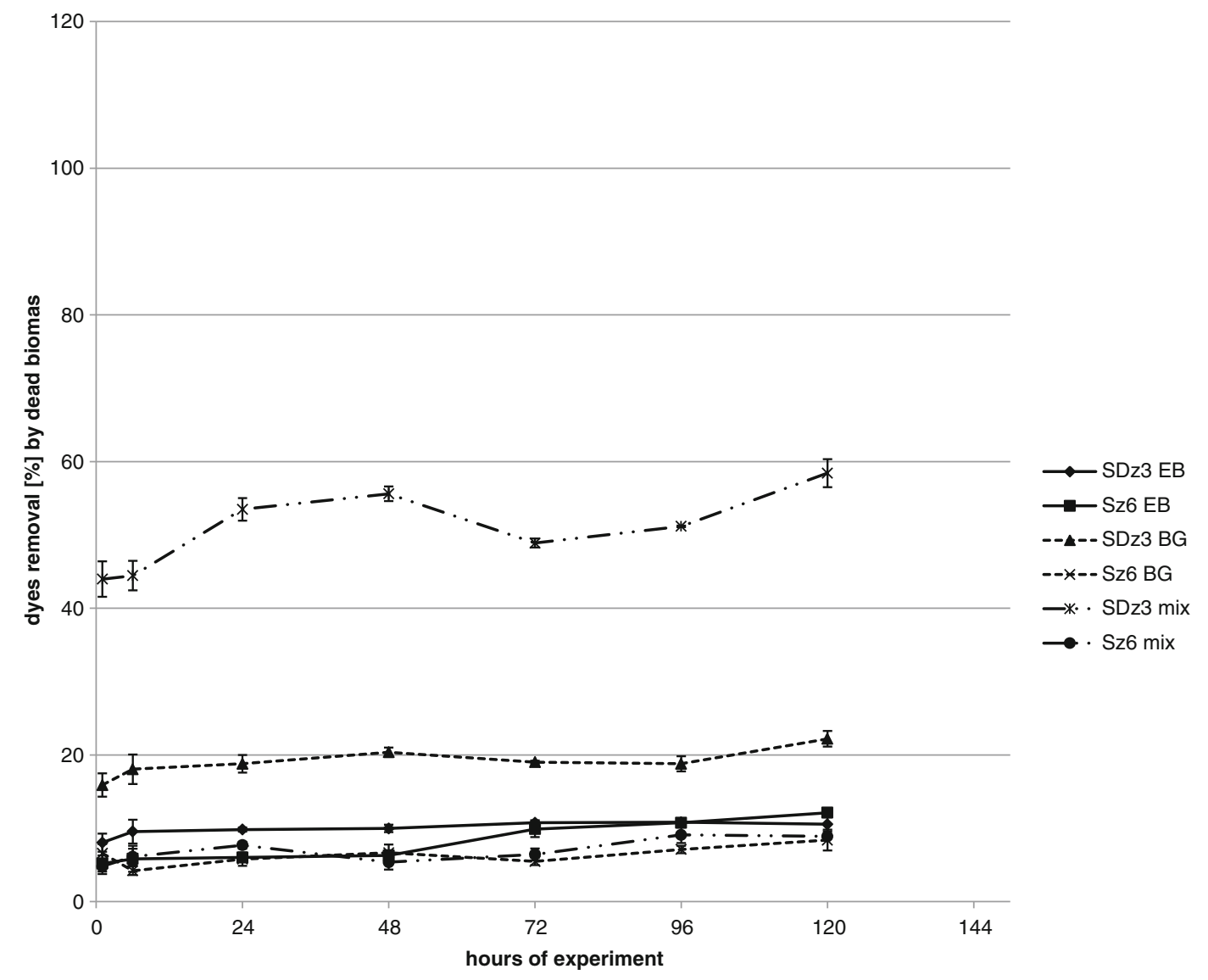

Fig. 3 Removal of dyes in samples with dead biomass 
abilities of Pseudomonas aeruginosa $\mathrm{BCH}$ was examined by Jadhav et al. (2011). Monochloro-sulphonated azo dye Remazol Red was degraded up to $97 \%$ within $20 \mathrm{~min}$. in static conditions.

Dead biomass was used for evaluation of sorption (Fig. 3). Sorption of dyes mixture by Sz6 was approximately $9 \%$. The best results of dye sorption were noticed in samples with dyes mixture with strain SDz3 (from $44 \%$ after $1 \mathrm{~h}$ up to $58.4 \%$ dye removal after $120 \mathrm{~h}$ ). As it is visible on Fig. 4, interaction between azo Evans blue and triphenylmethane brilliant green in mixture was observed. UV-Visible spectral scans (Fig. 4) show the displacement of major peak to $591 \mathrm{~nm}$. Probably, this phenomenon caused higher sorption of dyes mixture by strain SDz3. These results were surprising because so high sorption was not observed in sample with individual dyes. For strain SDz3, sorption of brilliant green after $120 \mathrm{~h}$ was approximately $20 \%$, Evans blue approximately $10 \%$ and for stain Sz6 approximately 8 and $12 \%$, respectively. Explanation of this phenomenon observed for dye mixture is difficult. Maybe it is connected with differences in quality and quantity of exopolysaccharides exuded by both tested strains what may influence on dyes sorption abilities when interaction between dyes happens. Wu et al. (2009) reported high effectiveness of dye removal by Pseudomonas otitidis WL-13 connected with adsorption on the biomass. Strain removed $95 \%$ of brilliant green and malachite green in concentration $500 \mu \mathrm{mol} \mathrm{l}^{-1}$ after $12 \mathrm{~h}$.

\subsection{Toxicity Evaluation}

Zootoxicity as well as phytotoxicity (Table 2) were also evaluated. Generally, zootoxicity and phytotoxicity after decolourisation process were lower or at the same level as in controls sample with dyes. Only in case of strain Sz6 with Evans blue incubated in static conditions zootoxicity increased from IV to V class. In these samples, complete decolourisation was observed and as it was suggested above transformation of azo dyes by azoreductases to toxic aromatic amines. In spite of high effectiveness of Evans blue removal in semistatic and shaken conditions, zootoxicity was at the same level as in control sample. In sample with dead biomass, removal reached less than $15 \%$ but the zootoxicity decreased

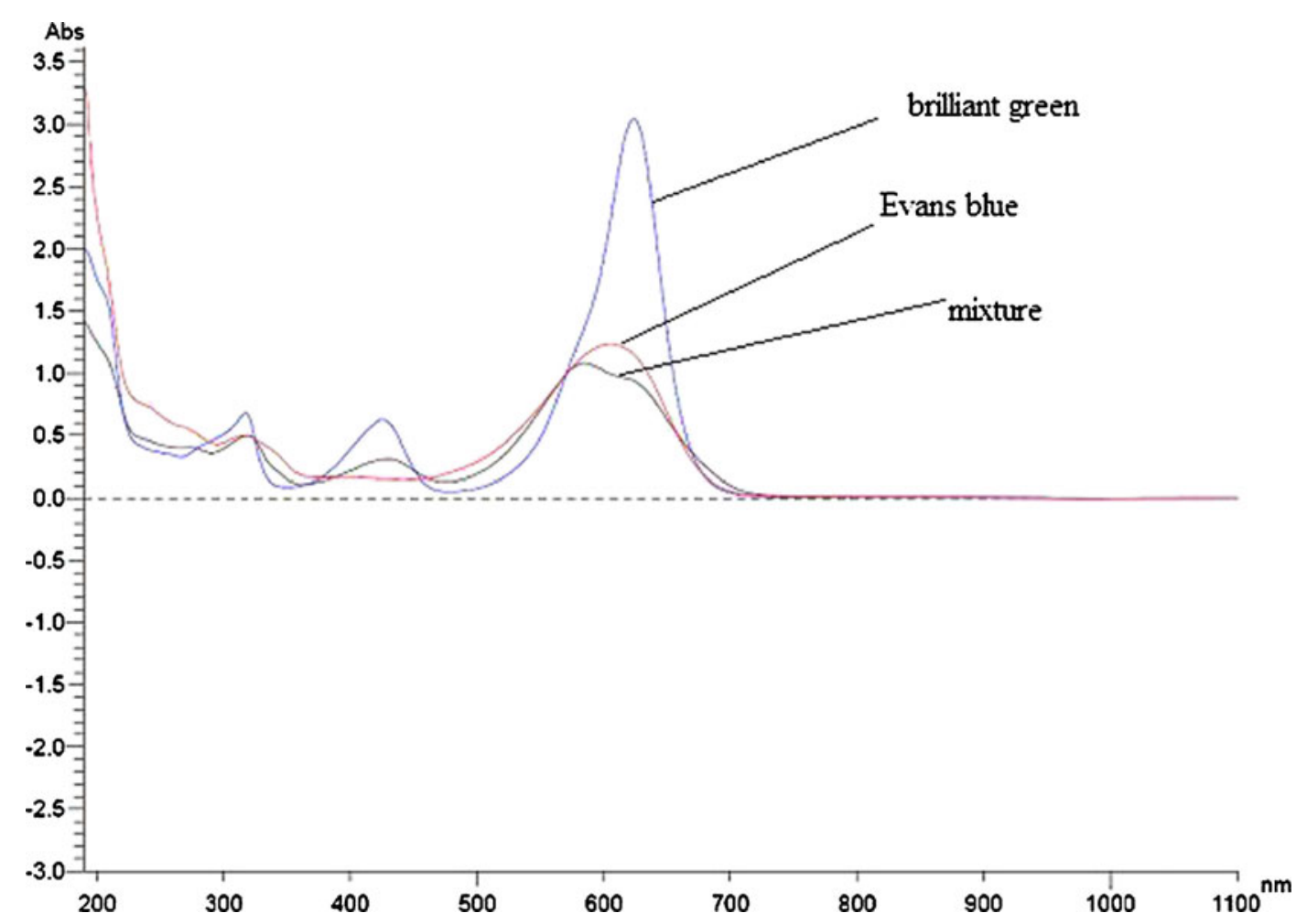

Fig. 4 UV-Visible spectral scans 
Table 2 Results of toxicity tests

\begin{tabular}{|c|c|c|c|c|c|c|c|c|}
\hline \multirow[t]{2}{*}{ Strain } & \multirow[t]{2}{*}{ Culture conditions } & \multirow[t]{2}{*}{ Dye } & \multicolumn{3}{|c|}{ Daphnia magna } & \multicolumn{3}{|l|}{ Lemna minor } \\
\hline & & & $\mathrm{EC}_{50}$ & TUa & Toxicity class & $\mathrm{EC}_{50}$ & TUa & Toxicity class \\
\hline \multirow[t]{12}{*}{ Sz6 } & \multirow[t]{3}{*}{ Static } & $\mathrm{EB}^{\mathrm{b}}$ & $0.8 \pm 0.32$ & 125 & V & n.d. ${ }^{\mathrm{a}}$ & $<0.4$ & I \\
\hline & & BG & $1.56 \pm 0.15$ & 64.1 & IV & $7.23 \pm 0.12$ & 13.8 & IV \\
\hline & & Mix & $4.69 \pm 0.09$ & 21.3 & IV & $7.81 \pm 0.09$ & 12.8 & IV \\
\hline & \multirow[t]{3}{*}{ Semistatic } & $\mathrm{EB}^{\mathrm{b}}$ & $9.43 \pm 1.08$ & 10.6 & IV & n.d. ${ }^{\mathrm{a}}$ & $<0.4$ & I \\
\hline & & BG & $18.69 \pm 2.17$ & 5.35 & III & $8 \pm 1.8$ & 12.5 & IV \\
\hline & & Mix & $4.42 \pm 0.27$ & 22.6 & IV & $9.43 \pm 0.79$ & 10.6 & IV \\
\hline & \multirow[t]{3}{*}{ Shaken } & $\mathrm{EB}^{\mathrm{b}}$ & $4.69 \pm 1.70$ & 21.3 & IV & $20.00 \pm 4.10$ & 5 & III \\
\hline & & BG & $4.69 \pm 0.46$ & 21.3 & IV & $10.42 \pm 1.1$ & 9.6 & III \\
\hline & & Mix & $2.31 \pm 0.1$ & 43.3 & IV & $9.43 \pm 1.44$ & 10.6 & IV \\
\hline & \multirow[t]{3}{*}{ Dead biomass } & $\mathrm{EB}^{\mathrm{b}}$ & $11.36 \pm 0.96$ & 8.8 & III & $23.26 \pm 8.20$ & 4.3 & III \\
\hline & & BG & $0.8 \pm 0.27$ & 125 & $\mathrm{~V}$ & $166.67 \pm 7.23$ & 0.6 & II \\
\hline & & Mix & $1.56 \pm 0.16$ & 64.1 & IV & $4.69 \pm 0.02$ & 21.3 & IV \\
\hline \multirow[t]{12}{*}{ SDz3 } & \multirow[t]{3}{*}{ Static } & $\mathrm{EB}^{\mathrm{b}}$ & $12.5 \pm 2.50$ & 8.0 & III & n.d. ${ }^{\mathrm{a}}$ & $<0.4$ & I \\
\hline & & $\mathrm{BG}$ & $18.69 \pm 3.1$ & 5.35 & III & $111.11 \pm 7.51$ & 0.9 & II \\
\hline & & Mix & $47.62 \pm 3.7$ & 2.1 & III & $1.56 \pm 0.47$ & 64.1 & IV \\
\hline & \multirow[t]{3}{*}{ Semistatic } & $\mathrm{EB}^{\mathrm{b}}$ & $37.04 \pm 2.80$ & 2.7 & III & n.d. ${ }^{\mathrm{a}}$ & $<0.4$ & I \\
\hline & & BG & $18.69 \pm 0.17$ & 5.35 & III & $111.11 \pm 5.66$ & 0.9 & II \\
\hline & & Mix & $11.49 \pm 2.2$ & 8.7 & III & $1.56 \pm 0.23$ & 64.1 & IV \\
\hline & \multirow[t]{3}{*}{ Shaken } & $\mathrm{EB}^{\mathrm{b}}$ & $18.87 \pm 3.20$ & 5.3 & III & $76.92 \pm 8.30$ & 1.3 & III \\
\hline & & BG & $9.43 \pm 0.76$ & 10.6 & IV & $35.71 \pm 2.13$ & 2.8 & III \\
\hline & & Mix & $7.81 \pm 0.16$ & 12.8 & IV & $1.56 \pm 0.11$ & 64.1 & IV \\
\hline & \multirow[t]{3}{*}{ Dead biomass } & $\mathrm{EB}^{\mathrm{b}}$ & $10.64 \pm 1.80$ & 9.4 & III & $24.39 \pm 9.50$ & 4.1 & III \\
\hline & & BG & $1.76 \pm 0.12$ & 56.7 & IV & $3.07 \pm 0.67$ & 32.6 & IV \\
\hline & & Mix & $52.63 \pm 5.14$ & 1.9 & III & $1.56 \pm 0.22$ & 64.1 & IV \\
\hline \multirow[t]{3}{*}{ Controls } & & $\mathrm{EB}^{\mathrm{b}}$ & $9.43 \pm 0.22$ & 10.6 & IV & $22.22 \pm 2.10$ & 4.5 & III \\
\hline & & BG & $0.98 \pm 0.07$ & 102 & V & $3.07 \pm 0.52$ & 32.6 & IV \\
\hline & & Mix & $0.92 \pm 0.15$ & 108.7 & $\mathrm{~V}$ & $1.2 \pm 0.01$ & 83.3 & IV \\
\hline
\end{tabular}

${ }^{\mathrm{a}}$ Not detected

${ }^{b}$ Results of toxicity of Evans blue decolourization end-products were published in Zabłocka-Godlewska et al. 2012

to III class. Such results of experiment proved that toxic metabolites were produced during Evans blue biotransformation by strain Sz6. In opposite to Sz6 in samples with SDz3, significant decrease of zootoxicity was observed (from IV to III class).

Franciscon et al. (2009a) reported that under microaerophilic conditions, toxicity of metabolites of azo dyes transformed by Staphylococcus arlettae for Daphnia magna decreased and in aerated samples, no toxicity was detected. The same results were reached by Franciscon et al. (2009b) for Klebsiella sp. strain VN-31.
High effectiveness of brilliant green removal by living biomass $(>77 \%$ ) was connected with significant decrease of zootoxicity (from V to IV or III class). Third class of zootoxicity was estimated in static and semistatic samples with SDz3 and semistatic with Sz6. Slight adsorption of brilliant green by dead biomass of SDz3 resulted in decrease of zootoxicity to III class when samples with dead biomass of Sz6 were extremely toxic (V class). Our previous study (Przystas et al. 2012) showed that bacterial decolourisation of brilliant green by Chryseomonas luteola and Burkholderia cepacia 
leads to decrease of zootoxicity but phytotoxicity was at the same level.

Dyes mixture was also effectively removed by living biomass of tested strains, and in all samples after $120 \mathrm{~h}$ of experiment, decrease of zootoxicity was observed (from V to IV class in case of strain Sz6, regardless of incubation method). High effectiveness of colour removal by strain SDz3 in semistatic and static conditions as well as by dead biomass caused decrease of zootoxicity to III class. Shaking connected with oxygenation of samples might change the metabolic pathway of dyes transformation that is why no so significant decrease was noticed. Even if decolourisation is very high, metabolites produced during the process might be different.

Lemna minor was more resistant to dyes as well as to bacterial metabolites. High removal of dyes mixture had no influence on phytotoxicity. Effective removal of brilliant green was connected with the decrease of phytotoxicity in samples with shaken biomass of strains Sz6 as well as strain SDz3 (III class), static samples with the same strain (II class) and dead biomass of strain Sz6 (even to II class of toxicity). Samples with Evans blue were classified even to I class of phytotoxicity (Sz6 and SDz3 incubated in static and semistatic conditions). Other samples (including dead biomass of both strains) were classified the same as controls to III class of phytotoxicity.

Findings of Cui et al. (2012) suggest that the biodegradation products of azo dyes transformation by bacterial consortia are less toxic to plants (Brassica pekinensis) than tested dyes. It proves that bacterial decolourisation of azo dyes can lead to their detoxification. Sheth and Dave (2009) reported that metabolites of Reactive Red biodegradation by Pseudomonas aeruginosa NGKCTS did not inhibit growth of soil microorganisms. Jadhav et al. (2010) reported no changes in DNA damage after decolourisation of mixture of reactive azo dyes by Pseudomonas consortium and weaker inhibition of seeds germination in samples with dyes metabolites. Decolourisation of Evans blue and brilliant green mixture by fungal strains was evaluated by Przystaś et al. (2013). Decrease of zootoxicity after treatment was noticed for all tested modifications and strains. In case of phytotoxicity, decrease was observed only in samples treated by single strains.

\section{Conclusions}

The present study of dyes decolourisation confirms high decolourisation effectiveness of Evans blue (EB), brilliant green (BG) and mixture (Mix) of them by two Pseudomonas strains (Sz6 and SDz3) isolated from different sites. Incubation conditions affected the rate of decolourisation. The best results were reached in shaken and semistatic samples. After $24 \mathrm{~h}$ of experiment in semistatic samples, BG removal reached up to $95.4 \%$, EB $72.8 \%$ and dyes mixture $88.9 \%$. After $120 \mathrm{~h}$, all tested dyes were completely removed. In most cases, strain Sz6 removed dyes faster and better than SDz3. Decrease of phyto- and zootoxicity of samples after $120 \mathrm{~h}$ was observed. Such results confirm possible usage of isolated strains to effective, cheap and environmental safe dyes removal also if they are present in wastewater in mixture.

Acknowledgments This research has been supported by a grant from the Ministry of Science and Higher Education (2007-2010)_research project number N523 178533.

Open Access This article is distributed under the terms of the Creative Commons Attribution License which permits any use, distribution, and reproduction in any medium, provided the original author(s) and the source are credited.

\section{References}

An, S. Y., Min, S. K., Cha, I. H., Choi, Y. L., Cho, Y. S., Kim, C. H., et al. (2002). Decolorization of triphenylmethane and azo dyes by Citrobacter sp. Biotechnology Letters, 24, 10371040 .

Azmi, W., Kumar Sani, R., \& Chand Banerjee, U. (1998). Biodegradation of triphenylmethane dyes. Enzyme Microbial Technology, 22, 185-191.

Banat, I. M., Nigam, P., Singh, D., \& Marchant, R. (1996). Microbial decolorization of textile-dye-containing effluents: a review. Bioresource Technology, 58, 217-227.

Chen, B. Y. (2002). Understanding decolorization characteristics of reactive azo dyes by Pseudomonas luteola: toxicity and kinetics. Processes Biochemical, 58, 217-227.

Chen, K., Wu, J., Liou, D., \& Hwang, S.-C. (2003). Decolorization of the textile dyes by newly isolated bacterial strains. Journal of Biotechnology, 101, 57-68.

Cui, D., Li, G., Zhao, D., Gu, X., Wang, C., \& Zhao, M. (2012). Microbial community structures in mixed bacterial consortia for azo dye treatment under aerobic and anaerobic conditions. Journal of Hazardous Materials, 221-222, 185-192. doi:10. 1016/j.jhazmat.2012.04.032.

Eichlerova, I., Homolka, L., \& Nerud, F. (2006). Synthetic dye decolorization capacity of white rot fungus Dichomitus squalens. Bioresource Technology, 97, 2153-2159. 
Forgacs, E., Cserhati, T., \& Oros, G. (2004). Removal of synthetic dyes from wastewaters: a review. Environment International Journa, 30, 953-971. doi:10.1016/j.envint.2004.02.001.

Franciscon, E., Zille, A., Dias Guimaro, F., Ragagnin de Menezes, C., Durrant, L. R., \& Cavaco-Paulo, A. (2009a). Biodegradation of textile azo dyes by facultative Staphylococcus arlettae strain $\mathrm{VN}-11$ using a sequential microaerophilic/aerobic process. International Biodeterioration and Biodegradation, 63, 280288. doi:10.1016/j.ibiod.2008.10.003.

Franciscon, E., Zille, A., Fantinatti-Garboggini, F., Serrano Silva, I., Cavaco-Paulo, A., \& Durrant, L. R. (2009b). Microaerophillic-aerobic sequential decolourization/biodegradation of textile azo dyes by a facultative Klebsiella sp. Strain VN-31. Process Biochemistry, 44, 446-452. doi:10. 1016/j.procbio.2008.12.009.

Hamid, M., \& Rehman, K. (2009). Potential applications of peroxidases. Food Chemistry, 115, 1177-1186. doi:10.1016/j. foodchem.2009.02.035.

Hu, T. L. (2001). Kinetics of azoreductase and assessment of toxicity of metabolic products from azo dyes by Pseudomonas luteola. Water Science and Technology, 43, 261-269.

Jadhav, J. P., Kalyani, A. A., Telke, A. A., Phugare, S. S., \& Govindwar, S. P. (2010). Evaluation of the efficacy of bacterial consortium for the removal of color, reduction of heavy metals, and toxicity from textile dye effluent. Bioresource Technology, 101, 165-173. doi:10.1016/j.biortech.2009.08.027.

Jadhav, B. S., Phugare, S. S., Patil, P. S., \& Jadhav, J. P. (2011). Biochemical biodegradation pathway of textile dye Remazol red and subsequent toxicological evaluation by cytotoxicity, genotoxicity and oxidative stress studies. International Biodeterioration and Biodegradation, 65, 733-743. doi:10. 1016/j.ibiod.2011.04.003.

Jang, M. S., Lee, Y. M., Kim, C. H., Lee, J. H., Kang, D. W., Kim, S. J., et al. (2005). Triphenylmethane reductase from Citrobacter sp. Strain KCTC 18061P: purification, characterization, gene cloning, and overexpression of functional protein in Escherichia coli. Applied Environmental Microbiology, 71, 7955-7960.

Jones, J. J., \& Falkinham, J. O. (2003). Decolorization of malachite green and crystal violet by waterborn pathogenic Mycobacteria. Antimicrobial Agents and Chemotherapy, 47, 2323-2326.

Kalyani, D. C., Telke, A. A., Dhanve, R. S., \& Jadhav, J. P. (2009). Ecofriendly biodegradation and detoxification of Reactive Red 2 textile dye by newly isolated Pseudomonas sp. SUK1. Journal of Hazardous Materials, 163, 735-742. doi: 10.1016/j.jhazmat.2008.07.020.

Khalid, A., Arshad, M., \& Crowley, D. (2008). Decolorization of azo dyes by Shewanella sp. under saline conditions. Appl. Microbiology Biotechnology, 79, 1053-1059.

Koyani, R. D., Sanghvi, G. V., Sharma, R. K., \& Rajput, K. S. (2013). Contribution of lignin degrading enzymes in decolourisation and degradation of reactive textile dyes. International Biodeterioration and Biodegradation, 77, 1-9.

Nachiyar, C. V., \& Rajakumar, G. S. (2005). Purification and characterization of an oxygen insensitive azoreductase from Psedomonas aeruginosa. Enzyme Microbiology Technology, 36, 503-509.

Nigam, P., McMullan, G., Banat, I. M., \& Marchant, R. (1996). Decolorization of effluent from the textile industry by a microbial consortium. Biotechnology Letters, 18(1), 117-120.

Ola, I. O., Akintokun, A. K., Akpan, I., Omomowo, I. O., \& Areo, V. O. (2010). Aerobic decolourizationof two reactive azo dyes under varying carbon and nitrogen source by Bacillus cereus. African Journal of Biotechnology, 9, 672-677.

Padamavathy, S., Sandhya, S., Swaminathan, K., Subrahmanyam, Y. V., \& Kaul, S. N. (2003). Comparison of decolorization of reactive azo dyes by microorganisms isolated from various source. Journal of Environmental Sciences, 15, 628-632.

Pointing, S. B., \& Vrijmoed, L. L. P. (2000). Decolorization of azo and triphenylmethane dyes by Pycnoporus sanguineus producing laccase as the sole phenoloxidase. World Journal Microbiology and Biotechnology, 16, 317-318.

Przystaś, W., Zabłocka-Godlewska, E., \& Grabińska-Sota, E. (2009). Screening of dyes decolorizing microorganisms strains. Polish Journal of Environmental Studies, 18(2B), 69-73.

Przystaś, W., Zabłocka-Godlewska, E., \& Grabińska-Sota, E. (2012). Biological removal of azo and triphenylmethane dyes and toxicity of process by-products. Water Air Soil Pollution, 223, 1581-1592. doi:10.1007/s11270-011-0966-7.

Przystaś, W., Zabłocka-Godlewska, E., \& Grabińska-Sota, E. (2013). Effectiveness of dyes removal by mixed fungal cultures and toxicity of their metabolites. Water Air Soil Pollution, 224, 1534. doi:10.1007/s11270-013-1534-0.

Salyers, A. A., \& Whitt, D. D. (2000). Microbiology: diversity, disease, and the environment (1st ed.). Washington: Wiley.

Sani, R. K., \& Banerjee, U. C. (1999). Decolorization of triphenylmethane dyes and textile and dye-stuff effluent by Kurthia sp. Enzyme Microbiol Technology, 24, 433-437.

Saratale, R. G., Saratale, G. D., Chang, J. S., \& Govindwar, S. P. (2010). Decolorization and biodegradation of reactive dyes and dye wastewater by a developed bacterial consortium. Biodegradation, 21, 999-1015. doi:10. 1007/s10532-010-9360-1.

Saratale, R. G., Saratale, G. D., Chang, J. S., \& Govindwar, S. P. (2011). Bacterial decolourization and degradation of azo dyes: a review. Journal of the Taiwan Institute of Chemical Engineers, 42, 138-157. doi:10.1016/j.jtice.2010.06.006.

Schlegel, H. G. (1993). General microbiology (7th ed.). Cambridge: Cambridge University Press.

Sharma, D. K., Saini, H. S., Singh, M., Chimni, S. S., \& Chandha, B. S. (2004). Isolation and characterization of microorganisms capable of decolorizing various triphenylmethane dyes. Journal Basic Microbiology, 44(1), 59-65. doi:10.1002/ jobm.200310334.

Sheth, N. T., \& Dave, S. R. (2009). Optimisation for enhanced decolourization and degradation of Reactive Red BS C.I. 111 by Pseudomonas aeruginosa NGKCTS. Biodegradation, 20, 827-836.

Silveira, E., Marques, P. P., Silva, S. S., Lima-Filho, J. L., Porto, A. L. F., \& Tambourgi, E. B. (2009). Selection of Pseudomonas for industrial textile dyes decolourization. Int. Biodeterior Biodegradation, 63, 230-235. doi:10.1016/j.ibiod.2008.09.007.

Singh, S., \& Pakshirajan, K. (2010). Enzyme activities and decolourization of single and mixed azo dyes by the white-rot fungus Phanerochaete chrysosporium. Int. Biodeterior Biodegradation, 64, 146-150. doi:10.1016/ j.ibiod.2009.11.003.

Solis, M., Solis, A., Perez, H. I., Mnjarrez, N., \& Flores, M. (2012). Microbial decolouration of azo dyes: a review. Process Biochemistry, 47, 1723-1748.

Somasiri, W., Ruan, W., Xiufen, L., \& Jian, C. (2006). Decolourization of textile wastewater containing acid dyes 
in UASB reactor system under mixed anaerobic granular sludge. Electronic J Environ Agricul Food Chem, 5(1), 1224-1234.

Srinivasan, A., \& Viraraghavan, T. (2010). Decolorization of dye wastewater by biosorbents: a review. Journal of Environmental Management, 91, 915-1929. doi:10.1016/j. jenvman.2010.05.003.

Stolz, A. (2001). Basic and applied aspects in the microbial degradation of azo dyes. Applied Microbiology and Biotechnology, 56, 69-80. doi:10.1007/s002530100686.

Swamy, J., \& Ramsay, J. A. (1999). The evaluation of white-rot fungi in the decoloration of textile dyes. Enzyme and Microbial Technology, 24, 130-137. doi:10.1016/S01410229(98)00105-7.

Tony, B. D., Goyal, D., \& Khanna, S. (2009). Decolorization of textile azo dyes by aerobic bacterial consortium. International Biodeterioration and Biodegradation, 63, 62469. doi:10.1016/j.ibiod.2009.01.003.

Vijaykumar, M. H., Vaishampayan, P. A., Shouche, Y. S., \& Karegoudar, T. B. (2007). Decolourization of naphtalenecontaining sulfonated azo dyes by Kerstersia sp. Strain VKY1. Enzyme Microbial Technology, 40, 204-211. doi:10. 1016/j.enzmictec.2006.04.001.

Wang, J., Qiao, M., Wei, K., Ding, J., Liu, Z., Zhang, K., et al. (2011). Decolorizing activity of malachite green and its mechanism involved in dye biodegradation by Achromobacter xylosoxidans MG1. Journal of Molecular Microbiology and Biotechnology, 20, 220-227. doi:10. 1159/000330669.
Wang, J., Gao, F., Liu, Z., Qiao, M., Niu, X., et al. (2012). Pathway and Molecular Mechanisms for Malachite Green Biodegradation in Exiguobacterium sp. MG2. PLoS ONE, 7(12), e51808. doi:10.1371/journal.pone.0051808.

Wu, J., Jung, B., Kim, K., Lee, Y., \& Sung, N. (2009). Isolation and characterization of Pseudomonas otitidis WL-13 and its capacity to decolorize triphenylmethane dyes. Journal of Environmental Sciences, 21, 960-964. doi:10.1007/s00253012-4476-3.

Wu, Y., Xiao, X., Xu, C., Cao, D., Du, D. (2012). Decolorization and detoxification of a sulfonated triphenylmethane dye aniline blue by Shewanella oneidensis MR-1 under anaerobic conditions. Appl Microbiol Biotechnol, Published online: http://www.ncbi.nlm.nih.gov/pubmed/23053116. Accessed 11 October 2012. doi; 10.1007/s00253-012-4476-3

Younes, S., Bouallagui, Z., \& Sayadi, S. (2012). Catalytic behavior and detoxifying ability of an atypical homotrimeric laccase from the thermophilic strain Scytalidium thermophilum on selected azo and triarylmethane dyes. Journal of Molecular Catalysis B: Enzymatic, 79, 41-48.

Zabłocka-Godlewska, E., Przystaś, W., \& Grabińska-Sota, E. (2009). Decolourization of triphenylmethane dyes and ecotoxicity their end products. Environment Protection Engineering, 35(1), 161-169.

Zabłocka-Godlewska, E., Przystaś, W., \& Grabińska-Sota, E. (2012). Decolourization of diazo Evans blue by two strains of Pseudomonas fluorescens isolated from different wastewater treatment plants. Water, Air, and Soil Pollution, 223, 5259-5266. doi:10.1007/s11270-012-1276-4. 